\title{
Celebrating 60 years of corneal transplant in Hong Kong
}

This article was published on 12 Nov 2021 at www.hkmj.org.

KW Kam ${ }^{1,2}$, FRCS (Glasg), MSc Epidemiology (London), Victoria WY Wong, 2,3,4, FRCSEd, FRCOphth, Vanissa WS Chow ${ }^{5}$, FRCSEd, FCOphthHK, Evan PF Yiu', FRCS (Glasg), FHKAM (Ophthalmology), Alvin L Young ${ }^{1,2}$ * , MMedSc (Hons), FRCOphth

\author{
${ }^{1}$ Department of Ophthalmology and Visual Sciences, Prince of Wales Hospital, Hong Kong \\ ${ }^{2}$ Department of Ophthalmology and Visual Sciences, The Chinese University of Hong Kong, Hong Kong \\ ${ }^{3}$ HKU Health System, Li Ka Shing Faculty of Medicine, The University of Hong Kong, Hong Kong \\ ${ }^{4}$ Department of Ophthalmology, Queen Mary Hospital and Grantham Hospital, Hong Kong \\ ${ }^{5}$ Department of Ophthalmology and Visual Sciences, Hong Kong Eye Hospital, Hong Kong \\ ${ }^{6}$ Tuen Mun Eye Centre, Hong Kong \\ *Corresponding author: youngla@ha.org.hk
}

Hong Kong Med J 2021;27:458-60

https://doi.org/10.12809/hkmj219671

Visual restoration through transplantation was limited to animal experiments until the first successful human corneal transplant more than a century ago in the Czech Republic area. ${ }^{1}$ Nowadays, corneal transplant/keratoplasty is one of the most commonly performed transplantation globally. However, 4.2 million people still have corneal blindness making it the fourth leading cause of blindness according to the World Health Organization, and graft scarcity remains a challenge. ${ }^{2}$

In Hong Kong, the first corneal transplant was performed in 1961 at Tung Wah Eastern Hospital. The expatriate surgeons performed many corneal transplants using fresh corneas from American eye banks (Fig a, b). This led to the establishment of the Hong Kong Eye Bank (HKEB) and Research Foundation in $1962 .{ }^{3}$

In the early years, the HKEB functioned mainly as a distributing centre, because local donation was rare. The concept of eye donation after death was not widely accepted, because local eye surgeons were sceptical regarding the success rate of corneal transplant in the era before microscopic surgery, and many local citizens subscribed to Confucian's ideology of 'filial piety', that is, a person's body, hair, and skin are gifts from their parents that should not be damaged. As a result, the HKEB had to rely on imported tissues from the International Eye Bank in Sri Lanka. During the 1970s to 80s, between 20 and 40 corneas were flown to Hong Kong annually which was insufficient to meet the local demand.

In the following decade there was a gradual acceptance of organ donation after death, as solid organ transplantation became available, society became more Westernised, and levels of education and public awareness were increased. Moreover, a shortage of burial plots led to a shift to cremation, weakening the concept of preserving a whole body for the afterlife. In the 90s, even patients with unilateral corneal blindness were keen to undergo surgery. To address soaring demand and the variable quality of tissue from Sri Lanka, the HKEB started harvesting corneas from local donors in 1992. The quality of locally harvested cornea continued to improve, and in 1997, importation from Sri Lanka was stopped.

Since 2000, the Hospital Authority (HA) of Hong Kong assumed responsibility for managing organ supply, and the HKEB was renamed the HA Lions Eye Bank. Management was later transferred to the Hong Kong Eye Hospital from December 2009 and was again renamed the HA Eye Bank (HAEB) from July 2016.

The HAEB has made great strides in governance, quality, safety, personnel training, and credentialing in meeting international standards. Strategic partnerships with leading eye banks have provided opportunities for progress. Since 2015, HAEB has collaborated with Sight Life on quality certification and entered into a global partnership with Sight Life in 2017. This has strengthened the HAEB in the regional eye banking scene. This is reflected in the fact that $>300$ corneal buttons have been harvested annually since 2017. As of 31 December 2020, 280 patients were on the waiting list for a corneal transplant. The average waiting time has now shortened to around 1 year. The youngest donor was a 20-month-old infant and the oldest cornea recipient was a centenarian. Unfortunately, similar to other transplant activities, donation and harvest rates have been adversely affected by the coronavirus disease 2019 pandemic.

Graft scarcity remains the limiting factor for the total number of keratoplasty procedures performed each year. A global survey revealed that 12.7 million people were waiting for a corneal transplant and only one in 70 of those would receive a cornea. ${ }^{4}$

Novel surgical techniques emerged to selectively replace diseased corneal layers in the 


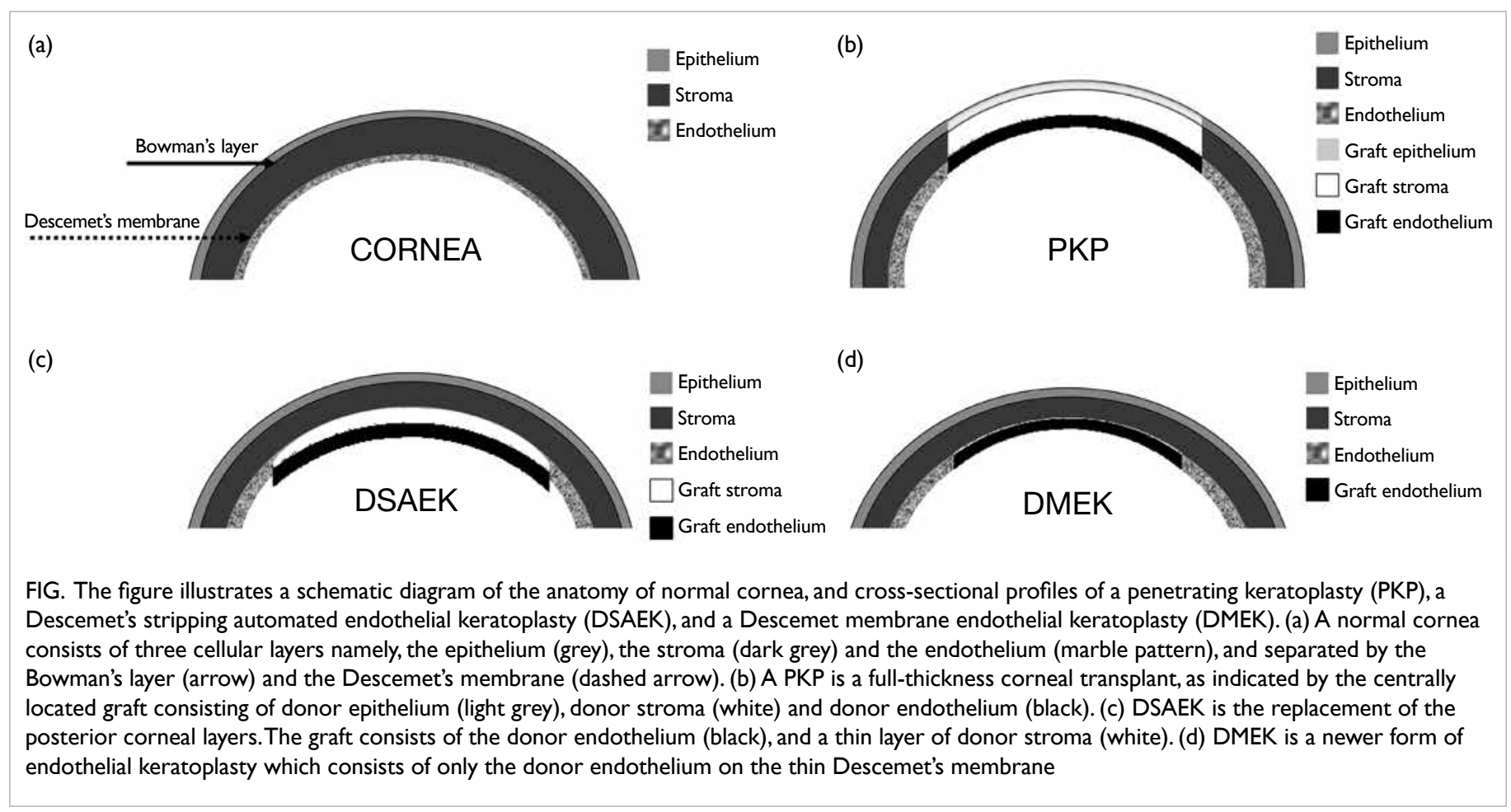

form of lamellar keratoplasty. With the aid of ophthalmic microscopes, finer surgical instruments and equipment, corneal surgeons migrated towards partial-thickness corneal transplants. In addition to better visual outcomes and lower risks of rejection, a single donor cornea may be transplanted into two or more patients with different pathologies. ${ }^{5}$

One of the more popular forms of lamellar keratoplasty is endothelial keratoplasty (Fig c), which replaces the diseased corneal endothelium and allows for the restoration of corneal clarity. ${ }^{6}$ In January 2005, the first Descemet stripping endothelial keratoplasty was successfully performed at the Prince of Wales Hospital. This operation required meticulous dissection of the donor cornea into a thicker anterior portion and a very thin posterior layer. The posterior lenticule $(<200 \mu \mathrm{m})$ was implanted into the patient's eye and secured only by a gas bubble without any need for suturing. Chinese eyes are known to be technically challenging; nonetheless, visual outcomes and complication profiles of procedures conducted in Hong Kong patients are comparable to international standards. ${ }^{7-9}$

As endothelial keratoplasty gained popularity, in 2008, the HKEB also started to pre-cut corneal tissues for surgeons. Having pre-cut tissues significantly reduces the operating time and obviates any risks of cancellation due to inadvertent graft damage during preparation.

In 2011, Tuen Mun Eye Centre performed the first Descemet membrane endothelial keratoplasty
(DMEK). ${ }^{10}$ This form of endothelial keratoplasty involves a much thinner donor than Descemet stripping endothelial keratoplasty, yielding the potential of less rejection risk and better vision (Fig d). As this membrane is extremely thin and delicate, accidental tears during preparation may occur leading to wastage. This must be weighed against graft shortages. Recently, a modified endotheliumin technique utilising a pull-through device was developed in Singapore. ${ }^{11}$ This technique was first applied at the Caritas Medical Centre in late 2020.

In February 2013, the HAEB updated the local criteria for cornea donation in accordance with American and European standards. ${ }^{12}$ The pool of potential donors was thus expanded as patients with solid organ malignancy were able to donate their corneas after death. In August 2018, The Chinese University of Hong Kong Jockey Club Ophthalmic Microsurgical Training Programme started the first penetrating keratoplasty simulated training for young ophthalmologists. As DMEK gains popularity, the HAEB will advance to preparation of pre-stripped DMEK grafts for surgeons. In May 2021, the HAEB organised the first territory-wide DMEK wet lab for corneal surgeons to gain hands-on experience with stripped endothelial grafts. This was followed by a wet lab organised by the Caritas Medical Centre on their experience of endothelium-in DMEK.

Common to solid organ grafting, there is a limited lifespan for any transplanted corneal graft. In cases where further grafts are not indicated, one 
could resort to artificial corneas. Apart from the more established osteo-odonto-keratoprosthesis ${ }^{13}$ and Boston keratoprosthesis, newer forms of artificial corneas are being developed.

Corneal surgeons are excited about the potential rho-kinase inhibitors medical therapy, which could restore corneal endothelial health. The use of cultivated human corneal endothelial cells and injecting such into the anterior chamber will likely revolutionise the concept of corneal transplant. ${ }^{14}$

As we gain knowledge in corneal genetics, we may even be able to prevent corneal degeneration from the outset with genetic therapy. ${ }^{15}$

\section{Author contributions}

Concept or design: AL Young.

Acquisition of data: All authors.

Analysis or interpretation of data: All authors.

Drafting of the manuscript: KW Kam.

Critical revision of the manuscript for important intellectual content: AL Young.

All authors had full access to the data, contributed to the study, approved the final version for publication, and take responsibility for its accuracy and integrity.

\section{Conflicts of interest}

All authors have disclosed no conflicts of interest.

\section{Acknowledgement}

The authors would like to acknowledge the tremendous support and contributions from Ms Catherine Wong, Manager of the Hong Kong Eye Bank.

\section{Funding/support}

This study received no specific grant from any funding agency in the public, commercial, or not-for-profit sectors.

\section{Ethics approval}

Ethics approval is not required for this commentary which did not involve human or animal subjects.

\section{References}

1. Crawford AZ, Patel DV, McGhee CN. A brief history of corneal transplantation: from ancient to modern. Oman I Ophthalmol 2013;6(Suppl 1):S12-7.
2. Wong KH, Kam KW, Chen LJ, Young AL. Corneal blindness and current major treatment concern-graft scarcity. Int J Ophthalmol 2017;10:1154-62.

3. Ho PC. Thirty-five years of eye banking in Hong Kong-a metamorphosis and a commitment renewed. Hong Kong J Ophthalmol 1997;1:19-24.

4. Gain P, Jullienne R, He Z, et al. Global survey of corneal transplantation and eye banking. JAMA Ophthalmol 2016;134:167-73.

5. Young AL, Kam KW, Jhanji V, Cheng LL, Rao SK. A new era in corneal transplantation: paradigm shift and evolution of techniques. Hong Kong Med J 2012;18:509-16.

6. Young AL, Rao SK, Cheng LL, Lam PT. Endothelial keratoplasty. Hong Kong J Ophthalmol 2008;12:25-32.

7. Li AL, Kwok RP, Kam KW, Young AL. A 5-year analysis of endothelial vs penetrating keratoplasty graft survival in Chinese patients. Int J Ophthalmol 2020;13:1374-7.

8. Young AL, Kwok RP, Jhanji V, Cheng LL, Rao SK. Longterm outcomes of endothelial keratoplasty in Chinese eyes at a University Hospital. Eye Vis (Lond) 2014;1:8.

9. Young AL, Rao SK, Lam DS. Endothelial keratoplasty: where are we? Clin Exp Ophthalmol 2008;36:707-8.

10. Monnereau C, Quilendrino R, Dapena I, et al. Multicenter study of descemet membrane endothelial keratoplasty: first case series of 18 surgeons. JAMA Ophthalmol 2014;132:1192-8.

11. Ang M, Mehta JS, Newman SD, Han SB, Chai J, Tan D. Descemet membrane endothelial keratoplasty: preliminary results of a donor insertion pull-through technique using a donor mat device. Am J Ophthalmol 2016;171:27-34.

12. Hospital Authority. Cluster Presentation ProgrammeKowloon Central Cluster. Eye Bank and Cornea Donation Service in Hong Kong. 2021. Available from: https://www. ha.org.hk/haho/ho/cad_bnc/HAB-P310.pdf. Accessed 6 Jul 2021.

13. Lam NM, Rao SK, Young AL, Cheng LL, Lam DS. Modified Osteo-Odonto Keratoprosthesis (MOOKP) in patients with severe anterior segment disease: Our Hong Kong Experience. ASCRS 2008. Chicago, United States 2008. Available from: http://ascrs2008.abstractsnet. com/handouts/000153_Modified_Osteo-Odonto_ Keratoprosthesis_(MOOKP)_in_patients.ppt. Accessed 6 Jul 2021.

14. Kinoshita S, Koizumi N, Ueno M, et al. Injection of cultured cells with a ROCK inhibitor for bullous keratopathy. N Engl J Med 2018;378:995-1003.

15. Sarnicola C, Farooq AV, Colby K. Fuchs endothelial corneal dystrophy: update on pathogenesis and future directions. Eye Contact Lens 2019;45:1-10. 